\title{
Monitoring the bulk milk antibody response to bovine viral diarrhea in dairy herds vaccinated with inactivated vaccines
}

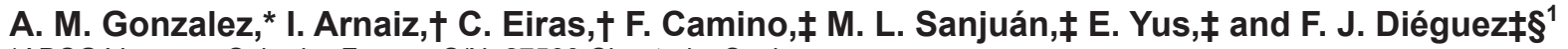 \\ ${ }^{*}$ ADSG Vacasan, Sobreira-Fornas, S/N, 27500 Chantada, Spain \\ †Animal Health and Production Laboratory of Galicia, Av. Madrid 77, 27002 Lugo, Spain \\ łInstitute of Food Analysis and Research (Animal Health and Epidemiology Unit), Veterinary Faculty of Lugo, Santiago de Compostela University, \\ Campus Universitario, 27002 Lugo, Spain \\ §Anatomy and Animal Production Department, Veterinary Faculty of Lugo, Santiago de Compostela University, Campus Universitario, \\ 27002 Lugo, Spain
}

\begin{abstract}
This study was designed to determine long-term responses in dairy herds after vaccination with 1 of 3 inactivated bovine viral diarrhea virus (BVDV) vaccines with regard to antibodies against p80 protein in bulk tank milk samples, as detected by ELISA. In the present study, 29 dairy herds were vaccinated with Bovilis BVD (MSD Animal Health, Milton Keynes, UK), 11 with Hiprabovis Balance (Laboratorios Hipra, Amer, Spain), and 9 with Pregsure BVD (Zoetis, Florham Park, NJ). In these herds, bulk tank milk samples were collected and examined at the time of the first vaccination and every 6 mo during a 3-yr period. Samples were analyzed with a commercial ELISA test for the p80 protein of BVDV. The results demonstrated that vaccination affected the level of antibodies against p80. Hence, vaccination status should be taken into consideration when interpreting bulk tank milk antibody tests.
\end{abstract}

Key words: bovine viral diarrhea virus (BVDV), vaccine, milk, diagnosis, ELISA

\section{INTRODUCTION}

Bovine viral diarrhea virus (BVDV) is a member of the genus Pestivirus in the family Flaviviridae. It causes bovine viral diarrhea (BVD), one of the most important diseases of cattle worldwide (Gunn et al., 2005). The genus Pestivirus comprises other important pathogens of livestock, including classical swine fever virus and border disease virus of sheep. Pestiviruses are able to cross species barriers to infect different hosts within the order Artiodactyla (Nettleton, 1990).

Bovine viral diarrhea causes considerable economic losses in dairies because of reduced milk production; increased mortality of young animals; and the repro-

Received December 18, 2013.

Accepted March 6, 2014.

${ }^{1}$ Corresponding author: franciscojavier.dieguez@usc.es ductive, respiratory, and intestinal problems that it produces. Infected animals are also more susceptible to other diseases (Greiser-Wilke et al., 2003; Diéguez et al., 2009). Gunn et al. (2004) noted that, without adequate control measures, BVDV infection might cost up to $£ 37$ per cow per year, which is equivalent to a loss of $£ 37,000$ for a 100 -cow herd over a 10 -yr period. In a few countries in which eradication campaigns have been implemented, the programs have shown to be cost effective (Houe, 2003). Vaccination programs still play an essential role in the prevention and control of the infection. Although protection is not $100 \%$ effective in every individual animal - due to some factors such as age, nutrition, genetics, and stage of pregnancy - it can be applied as an additional biosecurity measure (European Thematic Network on BVDV Control, 2001).

Two types of BVDV vaccines are currently available: modified live virus and killed virus. A possible concern with the use of BVDV vaccines is the interference of the induced antibody response with the interpretation of serological test results. Detection of antibodies is still the most rapid and cost-effective method to identify exposure to BVDV in herds. The most frequently used technique to estimate BVDV seroprevalence is ELISA. Control programs conducted in many countries are based on ELISA tests, which are run on bulk tank milk (BTM) samples periodically to assess the immune status of the sampled herds (Niskanen et al., 1991; Rikula et al., 2003; Hult and Lindberg, 2004; Eiras et al., 2012; Humphry et al., 2012)

The structural protein E2 of the virus is the major target for neutralizing antibodies, which confers protection after either infection or vaccination. Of the nonstructural proteins, the most studied is NS3 (p80). This protein is immunogenic and forms the basis of several commercially available immunoassays (Brownlie et al., 2000; Luo et al., 2012). Because nonstructural proteins are mainly produced during virus replication, cattle are more likely to develop antibodies to these antigens following natural infection. Thereby, it has been 
hypothesized that inactivated BVDV vaccines may not induce detectable antibodies against the p 80 protein. As a result, they would not interfere with ELISA tests (Graham et al., 2003). However, several studies have been inconclusive when trying to clarify whether vaccination with inactivated BVDV stimulates development of serum antibodies to p80 (Makoschey et al., 2007; Raue et al., 2011; Álvarez et al., 2012; Luo et al., 2012).

The aim of the present paper was to determine the long-term response in dairy herds to vaccination with 3 different inactivated BVDV vaccines with regard to antibodies against $\mathrm{p} 80$ protein, as detected by ELISA, in BTM samples.

\section{MATERIALS AND METHODS}

\section{Study Area and Herds Surveyed}

The study was carried out in northwestern Spain, which is the major cattle-farming region of the country, accounting for $38 \%$ of milk production in Spain and $1.5 \%$ in the European Union. In 2004, this was the first region in Spain to establish a voluntary BVDV control program. Farms willing to join the program are required to undertake additional BVDV serological testing on all cattle older than $1 \mathrm{yr}$, in addition to the compulsory annual testing for tuberculosis, brucellosis, and enzootic bovine leucosis. For those farms that participated in the voluntary BVDV eradication scheme, serum samples were analyzed with a commercial BVDV ELISA, based on detection of antibodies against p80. Subsequently, herd monitoring was also carried out by performing anti-p80 antibody ELISA on BTM samples every $6 \mathrm{mo}$ in combination with the testing of serum samples (by the same technique) from a selection of unvaccinated heifers.

\section{Study Design}

The same testing strategy as used in the control program was used for the study. Participating herds had to (1) be commercial dairies enrolled in the voluntary control program, (2) be free of active BVDV infection (since at least 2004), (3) have fewer than 25\% seropositive animals, and (4) be getting vaccinated for the first time. The number of herds that matched these criteria was 49. Twenty-nine out of the 49 herds were vaccinated with Bovilis BVD (MSD Animal Health, Milton Keynes, UK) by applying 2 doses 4 wk apart and then additional doses at 6-mo intervals. Eleven herds were vaccinated with Hiprabovis Balance (Laboratorios Hipra, Amer, Spain) and 9 with Pregsure BVD (Zoetis, Florham Park, NJ), in both cases applying 2 doses 4 wk apart, followed by booster vaccinations once a year. All vaccinations were performed following each manufacturer's instructions.

In the studied herds, BTM samples were collected and examined at the time of the first vaccination (t1) and every $6 \mathrm{mo}$, as previously mentioned, during a $3-\mathrm{yr}$ period (t2 to t7). Another 65 farms, also enrolled in the control program and free of active BVDV infection, were used as nonvaccinated controls.

\section{Serological Analysis}

The BTM samples were analyzed with a commercial ELISA test (BVDV p80 Ab; Pourquier Laboratories, Institut Pourquier, Montpellier, France). Analyses were performed following the recommendations of the manufacturer: samples were considered positive at a percentage inhibition (\%inh) of $\leq 80 \%$; \%inh was calculated from optical densities (OD) of samples and controls, as follows: \%inh $=(\mathrm{OD}$ of the analyzed sample/mean OD of the negative control) $\times 100$.

According to Eiras et al. (2012), low prevalence herds ( $<5 \%$ of seropositive animals) would have a \%inh $>84.3 \%$; herds with seroprevalence of 5 to $25 \%$ would have a \%inh from 84.3 to $56.7 \%$; those with seroprevalence of 25 to $65 \%$ would have a \%inh from 56.7 to $27.3 \%$; and high prevalence herds $(>65 \%)$, where BVDV is more likely to be present, would have a \%inh $<27.3 \%$.

\section{Statistical Analysis}

Data were analyzed with SPSS 11.0 (SPSS Inc., Chicago, IL). A one-way repeated-measures ANOVA was conducted to examine changes in \%inh obtained in the serial BTM samples using Wilks' Lambda statistic and polynomial contrast.

\section{RESULTS}

The mean \%inh of the 29 herds vaccinated with Bovilis BVD was 79.7 at t1. Six months after collecting the first BTM sample (t2), \%inh increased to 88.7 and tended to decrease toward the end of the study $(85.6$ at $\mathrm{t} 3,74.1$ at $\mathrm{t} 4,76.6$ at $\mathrm{t} 5,77.7$ at $\mathrm{t} 6$, and 72.9 at $\mathrm{t} 7$; Table 1). The largest decrease was observed between t3 and t4 (by $11.5 \%$; i.e., t 4 - t3). These differences in mean \%inh were statistically significant (Wilks' Lamb$\mathrm{da}=0.416 ; P=0.003)$. The polynomial contrasts also indicated a significant linear component $(F=12.997$; $P=0.001$ ). Accordingly, \%inh decreased linearly with time after vaccination (which implies a linear increase in the level of antibodies with successive vaccine doses). According to the manufacturer cut-off points, $44.8 \%$ $(13 / 29)$ of the herds were negative $(\%$ inh $>80)$ at $t 1$. 
Table 1. Level of antibodies (expressed as \% inhibition) against the p80 protein of bovine viral diarrhea virus in bulk tank milk samples by time (after vaccination) on farms that vaccinated with Bovilis BVD (MSD Animal Health, Milton Keynes, UK)

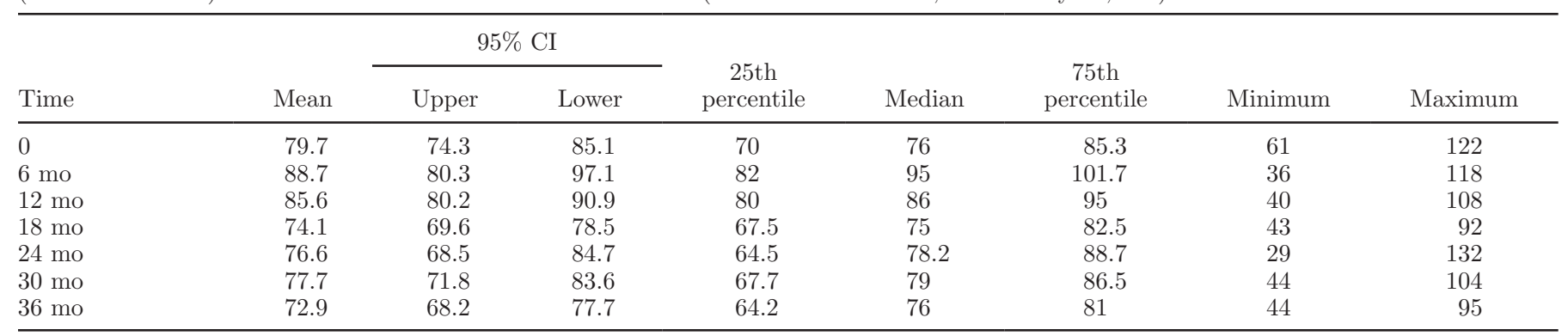

Of these farms, $15.4 \%(2 / 13)$ became positive at $\mathrm{t} 7$. None of the 29 herds reached levels of possible active infection (\%inh <27.3) during the 3-yr follow-up.

The 11 farms vaccinated with Hiprabovis Balance had a mean \%inh of 86.1 at t1. Significant variations were observed during the course of the study (Wilks' Lambda $=0.141 ; P=0.001): 74.7$ at $\mathrm{t} 2,82.3$ at $\mathrm{t} 3$, 80.3 at t4, 81.6 at t5, 73.8 at t6, and 77.8 at t7 (Table 2). However, polynomial contrasts tests failed to detect any trend in the evolution of \%inh. Using the manufacturer's interpretation guidelines for the test values, $81.8 \%(9 / 11)$ of the herds were negative at t1. Of these herds, $22.2 \%(2 / 9)$ suffered a considerable decrease in their test values, which was enough to consider the result positive (\%inh $\leq 80)$ at $\mathrm{t} 7$. As in the previous case, none of the herds showed levels of possible active infection during the study period.

Those farms vaccinated with Pregsure BVD showed a mean \%inh of 84.6 at t1. After that, \%inh greatly decreased: 54.5 at t2, 50.4 at t3, 37.8 at t4, 29,9 at t5, 33.6 at $\mathrm{t} 6$, and 38 at $\mathrm{t} 7$ (Wilks' Lambda $=0.017 ; P$ $=0.05$; Table 3$)$. The polynomial contrasts indicated that the decrease in \%inh was linear $(F=56.3 .23 ; P$ $<0.001$ ), which implies a linear increase in antibody levels. Overall, $77.8 \%(7 / 9)$ of the herds were negative at $\mathrm{t} 1$, and all of these herds became positive at t7. Six out of 9 herds $(66.7 \%)$ reached levels of possible active infection at some point of the follow-up period.
In the 65 control farms, \%inh was 69.3 at t1 and increased to 80.8 at t7. All new heifers sampled as part of the BVDV monitoring program in the studied herds were seronegative.

\section{DISCUSSION}

In countries or regions with high cattle density and high prevalence of BVDV, vaccination has been implemented as an additional measure of biosecurity to control the disease (Moennig et al., 2005; Luo et al., 2012). Response to vaccines varies among individuals; some individuals mount a strong, protective response to vaccination, whereas others mount a weak response or are nonresponders to the vaccine (Kimman et al., 2007). Even though vaccines are not $100 \%$ effective in every single animal, vaccination is effective at the herd level (Ridpath, 2013). The increased immunity at the herd level reduces the incidence of clinical diseases and the birth of persistently infected animals (Ridpath, 2013). In addition, some vaccines, such as Pregsure BVDV, produce a significantly higher virus antibody titer than other inactivated BVDV vaccines, as determined by seroneutralization and whole-virus antibody ELISA (Bastian et al., 2011; González et al., 2013).

Several studies have analyzed the ability of serum ELISA to discern between antibodies generated following vaccination with inactivated BVDV vaccines and

Table 2. Level of antibodies (expressed as \% inhibition) against the p80 protein of bovine viral diarrhea virus in bulk tank milk samples by time (after vaccination) on farms that vaccinated with Hiprabovis Balance (Laboratorios Hipra, Amer, Spain)

\begin{tabular}{|c|c|c|c|c|c|c|c|c|}
\hline Time & Mean & \multicolumn{2}{|c|}{$95 \%$ CI } & $\begin{array}{c}25 \text { th } \\
\text { percentile }\end{array}$ & Median & $\begin{array}{c}75 \text { th } \\
\text { percentile }\end{array}$ & Minimum & Maximum \\
\hline $12 \mathrm{mo}$ & 82.3 & 70.6 & 93.9 & 70 & 73 & 89 & 70 & 127 \\
\hline $18 \mathrm{mo}$ & 80.3 & 73.8 & 86.8 & 74 & 78 & 91 & 66 & 93 \\
\hline $24 \mathrm{mo}$ & 81.6 & 68.6 & 94.5 & 78 & 84 & 88 & 53 & 98 \\
\hline
\end{tabular}


Table 3. Level of antibodies (expressed as \% inhibition) against the p80 protein of bovine viral diarrhea virus in bulk tank milk samples by time (after vaccination) at the farms vaccinated with Pregsure BVD (Zoetis, Florham Park, NJ)

\begin{tabular}{|c|c|c|c|c|c|c|c|c|}
\hline Time & Mean & \multicolumn{2}{|c|}{$95 \% \mathrm{CI}$} & $\begin{array}{c}25 \text { th } \\
\text { percentile }\end{array}$ & Median & $\begin{array}{c}75 \text { th } \\
\text { percentile }\end{array}$ & Minimum & Maximum \\
\hline $6 \mathrm{mo}$ & 54.5 & 31.9 & 77 & 33.5 & 59 & 75.5 & 7 & 89 \\
\hline $12 \mathrm{mo}$ & 50.4 & 30.7 & 70.1 & 27.2 & 53.5 & 73.2 & 15 & 77 \\
\hline $18 \mathrm{mo}$ & 37.8 & 21.7 & 54 & 19.8 & 35.5 & 49.2 & 16 & 75 \\
\hline $24 \mathrm{mo}$ & 29.9 & 12 & 47.7 & 15.2 & 26.5 & 43.5 & 2 & 71 \\
\hline
\end{tabular}

those generated following natural BVDV infection. Some studies have indicated that the use of inactivated vaccines according to a standard schedule did not induce BVDV p80-specific antibodies and enabled differentiation between infected and vaccinated animals (DIVA; Makoschey et al., 2007; Álvarez et al., 2012). In contrast, Raue et al. (2011) demonstrated that antibody responses to BVDV vaccines cannot be clearly distinguished from responses seen in the early phase of natural infection; consequently, in the study of Raue et al. (2011), no commercial vaccine showed true marker qualities for DIVA using p80 ELISA tests.

Very few studies have addressed this issue in milk samples, despite BTM being frequently used in control programs. Identification of herds where the evolution shows a favorable trend based on a single BTM sample without the need for sampling individual cows, thereby allowing resources to be concentrated on herds at risk of active infection. Furthermore, BTM serology is a useful tool for ongoing surveillance of BVDV-free herds or herds in which the infection has been eliminated (Booth et al., 2013).

Kuijk et al. (2008) showed that BTM sample tests for $\mathrm{p} 80$-specific antibodies can be suitable for monitoring BVDV infection in a vaccinated herd, even after multiple vaccinations. However, our results indicated that vaccination affects BTM antibody results. Even in farms under the control program, where heifers that were incorporated every year to the lactation group had no contact with field BVDV, significant increases in antibody levels were often apparent after implementation of a vaccination program. Booth et al. (2013) also showed that vaccination caused transient increases in BTM antibody levels.

Because inactivated vaccines contain nonstructural proteins at low levels, positive ELISA results could be a consequence of the high sensitivity of the ELISA tests. According to Makoschey et al. (2007), the p80-specific antibody response decreases quickly after the vaccination. These authors suggested that test systems with a higher proportion of positive samples in vaccinated animals might be adapted by changing the cut-off level or choosing different dilution factors for the samples.

In contrast, on the control farms, a gradually steady decline in BTM antibody was observed, which was not detected in the vaccinated herds. Because the vaccinated herds were also enrolled in the control program, the decrease was likely due to the slow decline in antibody titer in individual animals but it could also be linked to culling rates, where replacement animals are free of BVDV (Moerman et al., 1993).

\section{CONCLUSIONS}

Our results indicated that vaccination of herds affects the level of antibodies against the p80 protein of the virus. The Pregsure BVD vaccine appeared to have strongest effect on the serological results, followed by Bovilis BVD and, to a lesser extent, Hiprabovis Balance. Although, according to previous studies, Pregsure BVD seems to produce a higher virus antibody titer, its use clearly interferes with diagnosis. Nevertheless, the use of the other 2 vaccines was compatible with a monitoring program, provided that vaccination is taken into account when interpreting the BTM antibody test, as the amount of antibodies produced by such vaccines is substantially less than the amount produced when a field virus infection takes place.

\section{REFERENCES}

Álvarez, M., J. Donate, and B. Makoschey. 2012. Antibody responses against non-structural protein 3 of bovine viral diarrhoea virus in milk and serum samples from animals immunized with an inactivated vaccine. Vet. J. 191:371-376.

Bastian, M., M. Holsteg, H. Hanke-Robinson, K. Duchow, and K. Cussler. 2011. Bovine neonatal pancytopenia: Is this alloimmune syndrome caused by vaccine-induced alloreactive antibodies? Vaccine 29:5267-5275.

Booth, R. E., M. P. Cranwell, and J. Brownlie. 2013. Monitoring the bulk tank milk antibody response to BVD: The effects of vaccination and herd infection status. Vet. Rec. 172:449.

Brownlie, J., I. Thompson, and A. Curwen. 2000. Bovine virus diarrhoea virus - Strategic decisions for diagnosis and control. In Pract. 22:176-187. 
Diéguez, F. J., E. Yus, M. J. Vilar, M. L. Sanjuán, and I. Arnaiz. 2009. Effect of the bovine viral diarrhea virus (BVDV) infection on dairy calf rearing. Res. Vet. Sci. 87:39-40.

Eiras, C., I. Arnaiz, M. L. Sanjuán, E. Yus, and F. J. Diéguez. 2012. Bovine viral diarrhea virus: Correlation between herd seroprevalence and bulk tank milk antibody levels using 4 commercial immunoassays. J. Vet. Diagn. Invest. 24:549-553.

European Thematic Network on BVDV Control. 2001. Position Paper on BVDV Control in Europe. Accessed Dec. 15, 2006. http:// www.bvdv-control.org/bilder/Position\%20paper\%20BVDV\%20 Control\%20EU\%20TN.pdf.

González, A. M., I. Arnaiz, E. Yus, C. Eiras, M. Sanjuán, and F. J Diéguez. 2013. Evaluation of long-term antibody responses to two inactivated bovine viral diarrhoea virus (BVDV) vaccines. Vet. J. http://dx.doi.org/10.1016/j.tvjl.2013.12.005.

Graham, D. A., A. German, K. A. Mawhinney, and E. A. Goodall. 2003. Antibody responses of naive cattle to two inactivated bovine viral diarrhoea virus vaccines, measured by indirect and blocking ELISAs and virus neutralization. Vet. Rec. 152:795-800.

Greiser-Wilke, I., B. Grummer, and V. Moennig. 2003. Bovine viral diarrhoea eradication and control programmes in Europe. Biologicals 31:113-118.

Gunn, G. J., H. W. Saatkamp, R. W. Humphry, and A. W. Stott. 2005. Assessing economic and social pressure for the control of bovine viral diarrhoea virus. Prev. Vet. Med. 72:149-162.

Gunn, G. J., A. W. Stott, and R. W. Humphry. 2004. Modelling and costing BVD outbreaks in beef herds. Vet. J. 167:143-149.

Houe, H. 2003. Economic impact of BVDV infections in dairies. Biologicals 31:137-143.

Hult, L., and A. Lindberg. 2004. BVD eradication in Sweden-The goal in sight. Rev. Portug. Cienc. Vet. 128:51.

Humphry, R. W., F. Brülisauer, I. J. McKendrick, P. F. Nettleton, and G. J. Gunn. 2012. Prevalence of antibodies to bovine viral diarrhoea virus in bulk tank milk and associated risk factors in Scottish dairy herds. Vet. Rec. 171:445.

Kimman, T. G., R. J. Vandebriel, and B. Hoebee. 2007. Genetic variation in the response to vaccination. Community Genet. 10:201217.
Kuijk, H., P. Franken, M. H. Mars, W. Bu de Weg, and B. Makoschey. 2008. Monitoring of BVDV in a vaccinated herd by testing milk for antibodies NS3 protein. Vet. Rec. 163:482-484.

Luo, Y., Y. Yuan, R. E. Ankenbauer, L. D. Nelson, S. B. Witte, J. A. Jackson, and S. K. W. Welch. 2012. Construction of chimeric bovine viral diarrhea viruses containing glycoprotein $\mathrm{E}^{\text {rns }}$ of heterologous pestivirus and evaluation of the chimeras as potential marker vaccines against BVDV. Vaccine 30:3843-3848.

Makoschey, B., D. Sonnemans, J. M. Bielsa, P. Franken, M. Mars, L. Santos, and M. Álvarez. 2007. Evaluation of the induction of NS3 specific BVDV antibodies using a commercial inactivated BVDV vaccine in immunization and challenge trials. Vaccine 25:61406145 .

Moennig, V., H. Houe, and A. Lindberg. 2005. BVD control in Europe: Current status and perspectives. Anim. Health Res. Rev. 6:63-74.

Moerman, A., P. J. Straver, M. C. de Jong, J. Quak, T. Baanvinger, and J. T. van Oirschot. 1993. A long term epidemiological study of bovine viral diarrhoea infections in a large herd of dairy cattle. Vet. Rec. 132:622-626.

Nettleton, P. F. 1990. Pestivirus infections in ruminants other than cattle. Rev. Off. Int. Epizoot. 9:131-150.

Niskanen, R., S. Alenius, B. Larsson, and S. O. Jacobsson. 1991. Determination of level of antibodies to bovine virus diarrhoea virus (BVDV) in bulk tank milk as a tool in the diagnosis and prophylaxis of BVDV infections in dairy herds. Arch. Virol. Suppl. 3:245-251

Raue, R., S. S. Harmeyer, and I. A. Nanjiani. 2011. Antibody responses to inactivated vaccines and natural infection in cattle using bovine viral diarrhoea virus ELISA kits: Assessment of potential to differentiate infected and vaccinated animals. Vet. J. 187:330-334.

Ridpath, J. F. 2013. Immunology of BVDV vaccines. Biologicals 41:14-19.

Rikula, U., T. Aaltonen, and O. Ruoho. 2003. BVD control in Finland 1998-2003 based on annual screening. Rev. Portug. Cienc. Vet. $128: 50$ 